\title{
Continuation Rates of the 52-mg Levonorgestrel-releasing Intrauterine System according to the Primary Reason for its Use
}

\section{Taxas de continuação com o sistema intrauterino de liberação de levonorgestrel de $52 \mathrm{mg}$ de acordo com o motivo principal de seu uso}

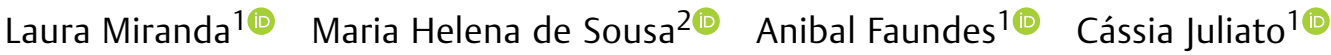 \\ 1 Universidade Estadual de Campinas, São Paulo, SP, Brazil \\ 2 Faculdade de Medicina de Jundiaí, Jundiaí, SP, Brazil \\ Address for correspondence Laura Miranda, Rua Lôbo de Resende, \\ 100, 13202-440, Jundiaí, SP, Brazil \\ (e-mail: miranda.laura88@gmail.com).
}

Rev Bras Ginecol Obstet 2021;43(4):291-296.

\begin{abstract}
Objective To evaluate whether continuation rates with the 52-mg levonorgestrelreleasing intrauterine system (LNG-IUS) up to 5 years after placement differed between women using the method exclusively for contraception and those using the device for medical reasons alone.

Methods A retrospective cohort study was conducted in a family planning clinic with 5,034 LNG-IUS users: 4,287 using the method exclusively for contraception and 747 for medical reasons alone. The continuation rate at 1 to 5 years of use was calculated by life table analysis.

Results Initially, the continuation rate was significantly higher in the contraception group: 85.8 versus 83.4 and 77.4 versus 76.0 per 100 women-years in the $1^{\text {st }}$ and $2^{\text {nd }}$ years of use, respectively. There were more discontinuations due to bleeding/spotting in the medical reasons group in the first two years. The discontinuation rate according

Keywords

- levonorgestrel IUS

- indication for use

- continuation rate

- amenorrhea

- bleeding and spotting

- counselling to reason for use was not significantly different from the third to the fifth year of use. No women discontinued due to amenorrhea in either group.

Conclusion The continuation rate was significantly higher in the contraception group in the first two years of use. Amenorrhea was not a reason for discontinuation in either group, suggesting that counselling in this respect was adequate. Nevertheless, counselling could perhaps have been better with regards to the expected long period of bleeding and spotting in the first two years after placement.
\end{abstract}

received

August 30, 2020

accepted

January 6, 2021
DOI https://doi.org/

10.1055/s-0041-1726056. ISSN 0100-7203. (c) 2021. Federação Brasileira de Ginecologia e Obstetrícia. All rights reserved.

This is an open access article published by Thieme under the terms of the Creative Commons Attribution License, permitting unrestricted use, distribution, and reproduction so long as the original work is properly cited. (https://creativecommons.org/licenses/by/4.0/)

Thieme Revinter Publicações Ltda., Rua do Matoso 170, Rio de Janeiro, RJ, CEP 20270-135, Brazil 


\section{Resumo}

\author{
Palavras-chave \\ - sistema liberador de \\ levonorgestrel (SIUS) \\ - indicação para uso \\ - taxa de continuação \\ - amenorreia \\ - sangramento e \\ microrragia \\ intermenstrual \\ - aconselhamento
}

Objetivo Avaliar a taxa de continuação até 5 anos de uso do sistema intrauterino liberador de 52-mg levonorgestrel por dia (SIU LNG) -IUS) é diferente entre mulheres que o usam exclusivamente como anticoncepcional que entre as que usam exclusivamente por razões médicas.

Métodos Estudo retrospectivo realizado em uma clínica de Planejamento Familiar 5.034 usuárias de SIU LNG, 4.287 que optaram pelo método apenas como anticoncepcional e 747 que o usavam somente por razoes médicas. A taxa de continuação de um até cinco ano foi calculada por meio de análise de tabela de vida

Resultados No início a taxa de continuação foi significativamente maior no grupo da anticoncepção: 85,8 versus 83,4 e 77,4 versus 76,0 por 100 anos-mulher no $1^{\circ}$ e $2^{\circ}$ ano de uso, respectivamente. Houve mais descontinuações por sangrado-manchado no grupo de razões médicas nos dos primeiros anos. A taxa de continuação não foi significativamente diferente desde o terceiro até o quinto ano de uso. Nenhuma mulher de ambos os grupos descontinuou por amenorreia.

Conclusão A taxa de continuação foi significativamente maior no grupo de anticoncepção durante os dos primeiros anos de uso. Amenorreia não foi motivo de descontinuação em ambos os grupos, sugerindo que a orientação a esse respeito foi adequada. Entretanto, a orientação referente ao longo período de sangramentos irregulares nos dois primeiros anos após a inserção, precisaria ser melhorado.

\section{Introduction}

The 52-mg levonorgestrel-releasing intrauterine system (LNG-IUS) was developed by the Population Council's International Committee for Contraception Research (ICCR) in the 1980 s as a contraceptive method. However, from the very beginning of its development, it was clear that the observed reduction in both the amount and duration of menstrual bleeding and the consequent improvement in hemoglobin levels constituted important non-contraceptive health benefits. ${ }^{1,2}$ This finding led to subsequent approval of the method as a treatment for women with heavy menstrual bleeding (HMB). ${ }^{3}$ The positive effect of this device in reducing pelvic pain in women with endometriosis, adenomyosis, and dysmenorrhea became evident a few years later and has been repeatedly confirmed. ${ }^{4,5}$ Currently, the medical effects of the 52-mg LNG-IUS have become a major indication for its use, being as important as its role as a contraceptive.

In the initial multicenter evaluations of this device, the continuation rates were not very impressive: less than $60 \%$ at 2 years and $33 \%$ at 5 years of use. The main reason for discontinuation reported by users in the earlier trials was amenorrhea. $^{2}$ Conversely, this side effect would be most welcome for women using the method to treat HMB or dysmenorrhea.

Consequently, our hypothesis was that continuation rates with the LNG-IUS would be better in women using the device for medical reasons, particularly those with HMB, compared with women using it purely for contraceptive purposes. The objective of the present study was to evaluate whether there was any difference in continuation rates of the LNG-IUS up to 5 years after placement of the device between two different cohorts of women: a group using the method exclusively for contraception and another group using the device for medical reasons alone.

\section{Methods}

This was a retrospective cohort study involving data collected systematically for the clinical records of all women initiating use of the 52-mg LNG-IUS (Mirena, Bayer Oy, Turku, Finland) at the family planning clinic of the Department of Obstetrics and Gynecology, School of Medical Sciences, Universidade de Campinas, Campinas, São Paulo, Brazil. The institution's internal review board approved the study protocol. No data were collected that would allow any of the women to be identified, thus ensuring the confidentiality of this information. Since this was a retrospective study based on data obtained from patients' medical records and because the identity of the women was maintained confidential, the requirement for informed consent was waived.

This clinic is one of the recipients of LNG-IUS devices provided at no cost by the International Contraceptive Access (ICA) Foundation. The clinic, then, offers the device to clients, also free of charge. Every woman who had decided to use the LNG-IUS at this clinic between January $3^{\text {rd }}, 2007$ and June $30^{\text {th }}$, 2015 was considered eligible for inclusion in the study.

Women who agreed to use the LNG-IUS for contraceptive reasons alone constituted the contraception group. These women were required to meet the following inclusion criteria: 1 ) age 14 to 50 years; 2) willing to use a LNG-IUS; 3 ) no desire to conceive within the next 12 months; 4) currently sexually active with a male partner; and 5) willing to return to the clinic at least once every 18 months to confirm that they continued to use the device and to register any possible event occurring during its use. 
Women at the same clinic and during the same time period who opted to use the LNG-IUS for the sole purpose of treating or preventing a medical condition constituted the medical reasons group. These women were required to meet the following inclusion criteria: 1) age 14 to 50 years; 2) suffering from medical disorders such as HMB, having a hematological disorder, in use of anticoagulant drugs, or suffering from dysmenorrhea or endometriosis-associated pelvic pain; 3) willing to return to the clinic at least once every 18 months to confirm that they continued to use the device and to register the occurrence of any possible event during its use.

Despite requesting that they return after 18 months of use, the general policy of the clinic was followed, which is to inform women that they do not need to return to the clinic if they do not have any problem related to the method used, following recommendations of the medical literature. ${ }^{6,7}$

The exclusion criteria were 1) women coming from another healthcare facility for the sole purpose of obtaining the device free of charge without being a client of this clinic, and 2 ) women requesting to use the LNG-IUS both for contraceptive purposes and for medical reasons. There were no active means of recording the follow-up of these women other than taking due note of every visit made by the participants to the clinic. Women who had come from other healthcare units or clinics for the sole purpose of obtaining the device and having it inserted were instructed to continue their followup at the clinic of origin, and, for that reason, were not included from this analysis.

The sample size was not calculated because no earlier studies were found on which to base estimations of expected differences between groups. The large number of women using the LNG-IUS at this clinic (over 4,000 in one group and over 700 in the other), however, allows us to be confident that the sample size was large enough to allow relatively small differences in the continuation rate to be identified, at least during the initial years of use.

\section{Statistical Analysis}

Clinical records stored in Microsoft Excel were transferred to a database constructed using the SPSS statistical software package, version 20.0 (IMDB Corp., Armonk, NY, USA), which was used for the statistical analysis. Two independent data entry clerks input the data in duplicate, and any inconsistencies were reviewed and corrected.

The main outcome variable was the continuation rate at 1 to 5 years of use of the LNG-IUS, calculated by life table analysis. The predictor variable consisted of the reason for using the method: either exclusively for contraception or exclusively for medical reasons. The control variables or potential confounders were age at the time of LNG-IUS placement, number of living children, years of schooling, and marital status.

Continuation rates after $1,2,3,4$, and 5 years of use of the LNG-IUS exclusively for contraceptive purposes were compared with the respective rates in the group of women using the method for medical reasons alone. The sociodemo- graphic characteristics of the women in each group were compared using Pearson chi-squared test or the chi-squared test with Yates correction.

The Cox multiple regression analysis was applied for each year of use, with five predictors/covariates to determine which were associated with the discontinuation rate. The backward method was used to select the variables. The significance level was established as $5 \%$ throughout the analysis.

\section{Results}

A total of 5,034 women who had opted to use a LNG-IUS were included in this analysis, with 4,287 using the device exclusively for contraception and 747 exclusively for medical reasons. Many women were lost to follow-up, particularly in the $1^{\text {st }}$ year after insertion, with 1,542 losses. Subsequently, 770 women were lost to follow-up in the $2^{\text {nd }}$ year, 435 in the $3^{\text {rd }}$ year, 263 in the $4^{\text {th }}$ year, and 210 in the $5^{\text {th }}$ year of use. Loss to follow-up was the main reason for the decline in the number of subjects under observation over time, with the number of users falling to 2,889 in the $2^{\text {nd }}$ year, 1,882 in the $3^{\text {rd }}$ year, 1,304 in the $4^{\text {th }}$ year and 938 in the $5^{\text {th }}$ year of observation. The women in the contraception group were significantly younger, had had fewer children, and were more likely to have a stable partner than those in the medical reasons group. No statistically significant differences were found between the groups with respect to years of schooling (-Table 1).

Table 1 Sociodemographic characteristics of the sample according to the women's reason for using the levonorgestrel-releasing intrauterine system

\begin{tabular}{|c|c|c|c|c|c|}
\hline \multirow[t]{3}{*}{ Characteristics of users } & \multicolumn{5}{|c|}{ Reason for use } \\
\hline & \multicolumn{2}{|c|}{$\begin{array}{l}\text { Contracep- } \\
\text { tion only }\end{array}$} & \multicolumn{2}{|c|}{$\begin{array}{l}\text { Medical } \\
\text { reasons } \\
\text { only }\end{array}$} & \multirow[t]{2}{*}{$p$-value } \\
\hline & $\mathrm{n}$ & $\%$ & $\mathrm{n}$ & $\%$ & \\
\hline \multicolumn{6}{|l|}{ Age (years) $(n=5,045)$} \\
\hline$\leq 24$ & 629 & 14.6 & 37 & 4.9 & $<0.001^{\mathrm{a}}$ \\
\hline $25-34$ & 2,124 & 49.4 & 222 & 29.7 & \\
\hline$\geq 35$ & 1,544 & 35.9 & 489 & 65.4 & \\
\hline \multicolumn{6}{|l|}{ Parity $(n=5,037)$} \\
\hline 1 & 2,190 & 51.0 & 302 & 40.6 & $<0.001^{\mathrm{a}}$ \\
\hline 2 & 1,633 & 38.0 & 283 & 38.1 & \\
\hline$\geq 3$ & 471 & 11.0 & 158 & 21.3 & \\
\hline \multicolumn{6}{|l|}{$\begin{array}{l}\text { Marital status } \\
(n=4,769)\end{array}$} \\
\hline In a stable union & 3,325 & 79.0 & 395 & 70.4 & $<0.001^{\mathrm{b}}$ \\
\hline No steady partner & 883 & 21.0 & 166 & 29.6 & \\
\hline \multicolumn{6}{|l|}{ Schooling $(n=4,750)$} \\
\hline$\leq 12$ years & 3146 & 75.0 & 407 & 73.5 & $0.473^{b}$ \\
\hline$\geq 13$ years & 1,050 & 25.0 & 147 & 26.5 & \\
\hline
\end{tabular}

${ }^{\mathrm{a}}$ Pearson chi-squared test; ${ }^{\mathrm{b}}$ Yates chi-squared test. 
294 Continuation Rates with the 52-mg Levonorgestrel-releasing Intrauterine System Miranda et al.

Table 2 Cumulative continuation rate of the levonorgestrel-releasing intrauterine system over 1 to 5 years of use, according to reason for use $(n=5,034)$

\begin{tabular}{|c|c|c|c|c|c|c|c|}
\hline \multirow{2}{*}{$\begin{array}{l}\text { Time } \\
\text { (years) }\end{array}$} & \multicolumn{3}{|l|}{ Contraception only } & \multicolumn{3}{|l|}{ Medical reasons only } & \multirow[t]{2}{*}{$p$-value ${ }^{a}$} \\
\hline & $\begin{array}{l}\text { Number } \\
\text { of users end of the year }\end{array}$ & $\begin{array}{l}\text { Continuation } \\
\text { rate (\%) }\end{array}$ & $\begin{array}{l}\text { SE rate } \\
(\%)\end{array}$ & $\begin{array}{l}\text { Number } \\
\text { of users end of the year }\end{array}$ & $\begin{array}{l}\text { Continuation } \\
\text { rate (\%) }\end{array}$ & $\begin{array}{l}\text { SE rate } \\
(\%)\end{array}$ & \\
\hline 1 & 4,287 & 85.8 & 0.6 & 747 & 83.4 & 1.5 & 0.002 \\
\hline 2 & 2,451 & 77.4 & 0.8 & 438 & 76.0 & 1.8 & 0.045 \\
\hline 3 & 1,559 & 70.1 & 0.9 & 323 & 71.3 & 2.0 & 0.121 \\
\hline 4 & 1,059 & 63.2 & 1.1 & 245 & 67.7 & 2.2 & 0.166 \\
\hline 5 & 752 & 57.5 & 1.2 & 186 & 61.2 & 2.5 & 0.186 \\
\hline
\end{tabular}

Abbreviations: N, Number of women at the start of the period analyzed; SE, standard error.

a'Wilcoxon-Gehan test.

The continuation rates for the entire group of LNG-IUS users were $85,77,70,64$, and 58 per 100 women-years at 1,2 , 3,4 , and 5 years after insertion, respectively. During the first 2 years of observation, the continuation rate was significantly higher in the contraception group, compared with the medical reasons group ( - Table 2 ). From the $3^{\text {rd }}$ to the $5^{\text {th }}$ years of use, this situation inverted, with a higher, although not significantly different, continuation rate in the medical reasons group (-Table $\mathbf{2}$ ).

Following the Cox multiple regression analysis, the significant association between using the device for contraceptive purposes alone and a higher continuation rate persisted for the first 2 years of use, while older age was associated with a significantly higher continuation rate at each of the 5 years of observation (-Table 3 ).

The main reason for discontinuation was expulsion of the device, followed by bleeding/spotting, and desire to conceive. Discontinuations due to acne or for other steroid-related reasons were few. No women discontinued use of the device

Table 3 Characteristics significantly associated with continuation rate after 1 to 5 years of use of the

levonorgestrel-releasing intrauterine system following the Cox multiple regression analysis $(n=4,728)^{a}$

\begin{tabular}{|c|c|c|c|}
\hline Time of use/ Characteristics & Coef. & SD coef. & $p$-value \\
\hline \multicolumn{4}{|l|}{ Up to one year } \\
\hline Age (years) & 0.020 & 0.004 & $<0.001$ \\
\hline Reason for use (contraception) & 0.281 & 0.074 & $<0.001$ \\
\hline \multicolumn{4}{|l|}{ Up to 2 years } \\
\hline Age (years) & 0.022 & 0.004 & $<0.001$ \\
\hline Reason for use (contraception) & 0.177 & 0.074 & 0.017 \\
\hline \multicolumn{4}{|l|}{ Up to 3 years } \\
\hline Age (years) & 0.021 & 0.004 & $<0.001$ \\
\hline \multicolumn{4}{|l|}{ Up to 4 years } \\
\hline Age (years) & 0.022 & 0.004 & $<0.001$ \\
\hline \multicolumn{4}{|l|}{ Up to 5 years } \\
\hline Age (years) & 0.023 & 0.004 & $<0.001$ \\
\hline 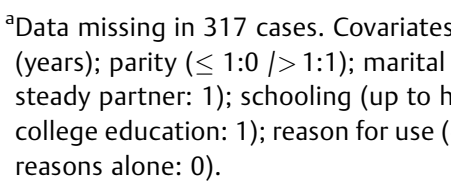 & $\begin{array}{l}\text { gh scho } \\
\text { ontrace }\end{array}$ & $\begin{array}{l}\text { in the analy } \\
\text { a stable un } \\
\text { l: } 0 \text { / at leas } \\
\text { tion alone: }\end{array}$ & $\begin{array}{l}\text { sis: age } \\
\text { on: } 0 \text { / no } \\
\text { t some } \\
1 / \text { medical }\end{array}$ \\
\hline
\end{tabular}

Table 4 Cumulative discontinuation rates up to 5 years of use of the levonorgestrel-releasing intrauterine system according to reasons for discontinuation and indication for using the method

\begin{tabular}{|c|c|c|c|c|c|}
\hline \multirow[t]{3}{*}{ Cause of discontinuation } & \multicolumn{5}{|c|}{ Indication for using the LNG-IUS } \\
\hline & \multicolumn{2}{|c|}{ Contraception } & \multicolumn{2}{|c|}{ Medical reasons } & \multirow[t]{2}{*}{$p$-value ${ }^{a}$} \\
\hline & $\mathrm{N}$ & (\%) & $\mathrm{N}$ & $(\%)$ & \\
\hline After 1 year & 4,287 & & 747 & & \\
\hline Expulsion & & 7.9 & & 11.6 & $<0.001$ \\
\hline Bleeding/spotting & & 0.8 & & 1.3 & 0.004 \\
\hline Pain & & 1.4 & & 0.8 & 0.320 \\
\hline Amenorrhea & & 0.0 & & 0.0 & \\
\hline Acne & & 0.2 & & 0.2 & 0.204 \\
\hline Desire to conceive & & 1.0 & & 0.4 & 0.004 \\
\hline Other & & 3.5 & & 2.9 & 0.061 \\
\hline After 2 years & 2,451 & & 438 & & \\
\hline Expulsion & & 10.5 & & 15.2 & $<0.001$ \\
\hline Bleeding/spotting & & 1.4 & & 2.1 & 0.023 \\
\hline Pain & & 2.4 & & 1.8 & 0.264 \\
\hline Amenorrhea & & 0.0 & & 0.0 & \\
\hline Acne & & 0.7 & & 0.2 & 0.194 \\
\hline Desire to conceive & & 4.0 & & 1.7 & 0.001 \\
\hline Other & & 5.8 & & 5.2 & 0.610 \\
\hline After 3 years & 1,559 & & 323 & & \\
\hline Expulsion & & 11.9 & & 16.3 & $<0.001$ \\
\hline Bleeding/spotting & & 1.8 & & 3.2 & 0.057 \\
\hline Pain & & 3.2 & & 1.8 & 0.257 \\
\hline Amenorrhea & & 0.0 & & 0.0 & \\
\hline Acne & & 1.0 & & 0.6 & 0.199 \\
\hline Desire to conceive & & 8.5 & & 4.2 & $<0.001$ \\
\hline Other & & 7.7 & & 6.5 & 0.807 \\
\hline After 4 years & 1,059 & & 245 & & \\
\hline Expulsion & & 13.3 & & 17.9 & $<0.001$ \\
\hline Bleeding/spotting & & 2.1 & & 3.2 & 0.087 \\
\hline Pain & & 4.3 & & 2.3 & 0.253 \\
\hline Amenorrhea & & 0.0 & & 0.0 & \\
\hline Acne & & 1.7 & & 0.6 & 0.227 \\
\hline Desire to conceive & & 11.7 & & 5.5 & 0.001 \\
\hline Other & & 10.6 & & 7.5 & 0.557 \\
\hline After 5 years & 752 & & 186 & & \\
\hline Expulsion & & 13.9 & & 18.9 & $<0.001$ \\
\hline Bleeding/spotting & & 2.6 & & 5.1 & 0.113 \\
\hline Pain & & 5.0 & & 2.3 & 0.238 \\
\hline Amenorrhea & & 0.0 & & 0.0 & \\
\hline Acne & & 2.0 & & 0.6 & 0.236 \\
\hline Desire to conceive & & 14.5 & & 6.6 & $<0.001$ \\
\hline Other & & 14.4 & & 12.0 & 0.489 \\
\hline
\end{tabular}

${ }^{\mathrm{a} C h i}$-squared test with Yates correction. 
because of amenorrhea in either of the two groups (-Table 4).

The discontinuation rate due to bleeding/spotting was greater in the medical reasons group compared with the contraception group throughout the entire 5 years of use; however, the difference was only statistically significant in the first 2 years of observation. There were significantly more expulsions throughout the 5 years of observation in the group of women using the method solely for medical reasons. Conversely, women using the method for contraception alone were significantly more likely to discontinue because they wanted to become pregnant compared with those using the device for medical reasons, throughout the entire 5-year study period (-Table 4).

\section{Discussion}

The present study shows that in this population of women living in a large Brazilian city of more than a million inhabitants and opting to use the LNG-IUS, amenorrhea was no longer a reason for discontinuation. This is largely due to very good counselling, particularly with respect to informing potential candidates that the possibility of experiencing reduced bleeding, fewer bleeding episodes, or no bleeding at all is high. Consequently, women who were not willing to stop menstruating on a regular basis probably chose not to use the method, while those who elected to use the LNG-IUS were no longer concerned about becoming amenorrheic. Similar results were found in a previous study conducted in the same city. ${ }^{8}$ On the other hand, the inconvenience of unpredictable bleeding or spotting became an important reason for discontinuation, particularly in the case of women using the device for medical reasons usually related to HMB or dysmenorrhea.

The present continuation rates were better than those reported in the initial evaluations of the device, when less than $60 \%$ of users continued with the LNG-IUS after 2 years, compared with $77 \%$ in the present study. ${ }^{2}$ Rates were also better than those reported from a more recent multicenter study conducted by the World Health Organization, particularly after 3 years (61.8 versus 70 per 100 women-years) and after 5 years of use ( 47.5 versus 58 per 100 women-years). ${ }^{9}$ The discontinuation rate in this study population was, however, similar to the rate found in the US-based Contraceptive Health Research Of Informed Choice Experience (CHOICE) study, which reported continuation rates of $88 \%$ (versus $85 \%$ ) at 1 year; $79 \%$ (versus $77 \%$ ) at 2 years; $62.5 \%$ (versus $64 \%$ ) at 4 years, and 51.7 (versus $58 \%$ ) at 5 years. ${ }^{10-12}$ In fact, the contraceptive services offered in our clinic parallel those provided in the US-CHOICE study in that all the methods, including the LNG-IUS, were supplied to the women at no cost.

One possible explanation for the relatively good results found in the present study is that this clinic is one of the most experienced in the world in the use of this method, having worked with the LNG-IUS since $1978 .{ }^{13}$ Hence, the healthcare professionals working here have a vast experience in counselling women interested in using the device. It would appear, however, that the explanations provided regarding the long period preceding amenorrhea, when the woman could experience bothersome spotting or even bleeding, are insufficient. The LNG-IUD user should be aware of this and be patient, knowing that these bleeding irregularities will pass with time. This is crucial for women using the method for medical reasons, whose expectation of avoiding menstruation is greatest.

The significantly higher expulsion rate in the group of women using the device as a treatment for HMB was expected and is in agreement with previous findings in this same clinic showing that expulsion is three times more likely in these women compared with those using the device for contraception alone. ${ }^{14}$ Most probably, some of these women had the device inserted during an episode of $\mathrm{HMB}$, when the uterine muscles are irritated and may cause uterine contractions that could result in expulsion.

The higher discontinuation rate due to a desire to conceive in the group of women using the device for contraceptive purposes alone was expected, since the women using the method for medical reasons alone were older and had already had more children compared with the contraception group.

The main limitation of the present study is the relatively high rate of loss to follow-up, which reached $26 \%$. Another study conducted with this same population showed that loss to follow-up was associated with a large proportion (>25\%) of college-educated LNG-IUS acceptors, a situation that is not typical of the clientele in this public healthcare clinic. ${ }^{15}$ Better-educated women with higher income levels are less dependent on the care provided at this family planning clinic and are better prepared to act according to the information given at insertion; thus, follow-up visits would not have improved performance if there were no complications during the use of the LNG-IUS. This, however, results in a high rate of loss to follow-up, which would potentially bias the results. In case the main reason for not returning to follow-up was the understanding that these visits were not required for the successful use of the method, it is possible that the continuation rate could have been better. Although such hypothesis is impossible to test, the opposite possibility, that users had the device removed in another clinic, is even less plausible.

The main lesson learned here is the need to provide careful and accurate information prior to the insertion of the device, focusing on the possibility of bothersome spotting and bleeding, which, although insignificant in terms of quantity, is unpredictable insofar as both timing and duration are concerned. This is particularly relevant in the case of women using the method for medical reasons if the expectation is to be free from menstruation with the use of the device. Although menstruation will not be painful, frequent bleeding, even in small quantities, is unacceptable to many women and they have the right to be adequately informed of this problem before deciding whether to use the device.

\section{Conclusion}

Although these results originate from one clinic within the Brazilian public healthcare service network, we believe that 
the recommendation may equally apply to any other sites where the LNG-IUS is available. Providing adequate counselling to women selecting a contraceptive device is an important component of the quality of care, and, in this case, information on the expected bleeding characteristics in the $1^{\text {st }}$ year of use of the LNG-IUS should be a focus of counseling everywhere. We expect that by improving this aspect of counseling in our clinic, the current relatively good continuation rate can further improve in the future.

\section{Contributions}

Laura Miranda and Anibal Faúndes prepared the research proposal, including this analysis, and collected the data. Laura Miranda and Anibal Faúndes wrote the first draft of the article, which was reviewed by Cássia Juliato and Maria Helena de Sousa. Maria Helena de Sousa was also responsible for the data analysis.

\section{Financial Support}

The present study received partial financial support from the Foundation for Research Support of the State of São Paulo (FAPESP) grant No. 2015/20504-9 and from the National Council for Scientific and Technological Development (CNPq, in the Portuguese acronym) grant No. 573747/2008-3. The International Contraceptive Access Foundation, Turku, Finland, has been donating the LNGIUS devices used at this clinic since 2007 under an unrestricted grant.

Conflict of Interests

The authors have no conflict of interests to declare.

\section{References}

1 Sivin I, Alvarez F, Diaz J, Diaz S, el Mahgoub S, Coutinho E, et al. Intrauterine contraception with copper and with levonorgestrel: a randomized study of the TCu 380Ag and levonorgestrel 20 mcg/day devices. Contraception. 1984;30(05):443-456. Doi: 10.1016/0010-7824(84)90036-2

2 Sivin I, Stern J, Diaz J, et al. Two years of intrauterine contraception with levonorgestrel and with copper: a randomized comparison of the TCu 380Ag and levonorgestrel $20 \mathrm{mcg} /$ day devices. Contraception. 1987;35(03):245-255. Doi: 10.1016/0010-7824(87) 90026-6

3 Luukkainen T, Toivonen J. Levonorgestrel-releasing IUD as a method of contraception with therapeutic properties. Contraception. 1995; 52(05):269-276. Doi: 10.1016/0010-7824(95)00210-2
4 Petta CA, Ferriani RA, Abrao MS, Hassan D, Rosa e Silva JC, Podgaec $\mathrm{S}$, et al. Randomized clinical trial of a levonorgestrel-releasing intrauterine system and a depot GnRH analogue for the treatment of chronic pelvic pain in women with endometriosis. Hum Reprod. 2005;20(07):1993-1998. Doi: 10.1093/humrep/deh869

5 Radzinsky VE, Khamoshina MB, Nosenko EN, Dukhin AO, Sojunov MA, Orazmuradov AA, et al. Treatment strategies for pelvic pain associated with adenomyosis. Gynecol Endocrinol. 2016;32(sup2, Suppl 2):19-22. Doi: 10.1080/09513590.2016.1232673

6 Hubacher D, Fortney J. Follow-up visits after IUD insertion. Are more better? J Reprod Med. 1999;44(09):801-806

7 Neuteboom K, de Kroon CD, Dersjant-Roorda M, Jansen FW. Follow-up visits after IUD-insertion: sense or nonsense? A technology assessment study to analyze the effectiveness of follow-up visits after IUD insertion. Contraception. 2003;68(02):101-104. Doi: 10.1016/s0010-7824(03)00111-2

8 Estanislau do Amaral MC, Hardy E, Hebling EM, Faúndes A. Menstruation and amenorrhea: opinion of Brazilian women. Contraception. 2005;72(02):157-161. Doi: 10.1016/j.contraception.2005.02.013

9 Rowe P, Farley T, Peregoudov A, Piaggio G, Boccard S, Landoulsi S, et al; IUD Research Group of the UNDP/UNFPA/WHO/World Bank Special Programme of Research; Development and Research Training in Human Reproduction. Safety and efficacy in parous women of a 52-mg levonorgestrel-medicated intrauterine device: a 7-year randomized comparative study with the TCu380A. Contraception. 2016;93(06):498-506. Doi: 10.1016/j.contraception.2016.02.024

10 Peipert JF, Zhao Q, Allsworth JE, Petrosky E, Madden T, Eisenberg $D$, et al. Continuation and satisfaction of reversible contraception. Obstet Gynecol. 2011;117(05):1105-1113. Doi: 10.1097/AOG.0b013e31821188ad

11 O'Neil-Callahan M, Peipert JF, Zhao Q, Madden T, Secura G. Twenty-four-month continuation of reversible contraception. Obstet Gynecol. 2013;122(05):1083-1091. Doi: 10.1097/AOG.0b013e3182a91f45

12 Diedrich JT, Madden T, Zhao Q, Peipert JF. Long-term utilization and continuation of intrauterine devices. Am J Obstet Gynecol. 2015;213(06):822.e1-822.e6. Doi: 10.1016/j.ajog.2015.08.077

13 Díaz J, Faúndes A, Díaz M, Marchi N. Evaluation of the clinical performance of a levonorgestrel-releasing IUD, up to seven years of use, in Campinas, Brazil. Contraception. 1993;47(02):169-175. Doi: 10.1016/0010-7824(93)90089-p

14 Diaz J, Bahamondes L, Monteiro I, Petta C, Hildalgo MM, Arce XE. Acceptability and performance of the levonorgestrel-releasing intrauterine system (Mirena) in Campinas, Brazil. Contraception. 2000;62(02):59-61. Doi: 10.1016/s0010-7824(00)00140-2

15 Miranda L, Figueiredo T, Faúndes A, Bahamondes L. Factors associated with loss to follow-up among acceptors of the levonorgestrel-releasing intrauterine system at a public-sector family planning clinic in Brazil. Jacobs J Gynecol Obstet. 2018;5(03):42 